\section{Intestinal perforation: a rare complication of percutaneous endoscopic jejunostomy removal}

Direct endoscopic percutaneous jejunostomy (DPEJ) was first described by Shike et al. 1987 [1] and since then has become increasingly popular [2]. Successful placement is achieved in up to $72 \%$ of patients. Immediate complications such as bowel perforation and serious bleeding have been reported in up to $22 \%$ of patients [3]. Currently, reports of complications during replacement of DPEJ are lacking. We report two cases of intestinal perforation related to the removal and replacement of DPEJ.

The first case was that of a 61-year-old man with recurrent aspiration, lung abscess, and bronchiectasia who had an uncomplicated insertion of DPEJ for longterm enteral nutrition. His clinical outcome improved significantly after 6 months and the DPEJ was no longer required. He was referred for DPEJ removal. The second case was that of a 71-year-old lady treated for neck cancer, who received long-term enteral nutrition via a percutaneous endoscopic gastrostomy (PEG) for 3 years. She suffered recurrent aspiration pneumonia and the PEG was changed to a DPEJ. After 9 months, she was referred for DPEJ replacement.
In both cases the DPEJ was removed using the manual traction technique, but the bumper was disrupted and was not retrieved. Due to concerns about smallintestinal obstruction, it was decided to retrieve the bumper endoscopically. Unfortunately, both patients developed signs of an acute abdomen after endoscopy. Abdominal radiography showed free gas under the diaphragm. A laparotomy was performed in both patients and the perforation at the site of the DPEJ insertion was repaired. A surgical jejunostomy was inserted in the female patient. In conclusion, we strongly recommend that enteroscopy should not be performed once the DPEJ has been removed from the stoma, and if the internal bumper becomes disrupted, it should be left to pass spontaneously.

Endoscopy_UCTN_Code_CPL_1AH_2AI

\section{N. Zschau, N. Nguyen, W. Tam, \\ M. Schoeman}

Department of Gastroenterology, Hepatology and General Medicine, Royal Adelaide Hospital, South Australia

\section{References}

1 Shike M, Schroy P, Ritchie MA et al. Percutaneous endoscopic jejunostomy in cancer patients previous gastric resection. Gastrointest Endosc 1987; 33: 372 - 374

2 Rumalla A, Baron TH. Results of direct percutaneous endoscopic jejunostomy, an alternative method for providing jejunal feeding. Mayo Clin Proc 2000; 75: 807-810

3 Maple JT, Petersen BT, Baron TH et al. Direct percutaneous endoscopic jejunostomy: outcomes in 307 consecutive attempts. Am J Gastroenterol 2005; 100: 2681 - 2688

\section{Bibliography}

DOI 10.1055/s-2007-995808

Endoscopy 2008; 40: E178

(c) Georg Thieme Verlag KG Stuttgart · New York . ISSN 0013-726X

\section{Corresponding author}

M. Schoeman, MD

Department of Gastroenterology, Hepatology and General Medicine

Royal Adelaide Hospital

North Terrace

Adelaide

SA 5000

Australia

Fax: +618-82225885

Mschoema@mail.rah.sa.gov.au 